This item was submitted to Loughborough's Research Repository by the author.

Items in Figshare are protected by copyright, with all rights reserved, unless otherwise indicated.

\title{
Mobilities and waiting: experiences of middle-aged Latvian women who emigrated and those who stayed put
}

PLEASE CITE THE PUBLISHED VERSION

https://doi.org/10.1080/0966369X.2018.1435512

\section{PUBLISHER}

Taylor \& Francis Group (@ Informa UK, Ltd)

\section{VERSION}

AM (Accepted Manuscript)

\section{PUBLISHER STATEMENT}

This work is made available according to the conditions of the Creative Commons Attribution-NonCommercialNoDerivatives 4.0 International (CC BY-NC-ND 4.0) licence. Full details of this licence are available at: https://creativecommons.org/licenses/by-nc-nd/4.0/

\section{LICENCE}

CC BY-NC-ND 4.0

\section{REPOSITORY RECORD}

Lulle, Aija. 2019. "Mobilities and Waiting: Experiences of Middle-aged Latvian Women Who Emigrated and Those Who Stayed Put". figshare. https://hdl.handle.net/2134/35585. 
Mobilities and waiting: experiences of middle-aged Latvian women who emigrated and those who stayed put

\author{
Aija Lulle b * $^{\text {b }}$ \\ ${ }^{a}$ Department of Geography, University of Latvia; ${ }^{b}$ Department of Social sciences, University \\ of Eastern Finland
}

Correspondence: *aija.lulle@lu.lv

\title{
Short biographical note
}

Aija LULLE holds a doctoral degree in Human Geography with specialisation in migration. Her research interests are clustered around migration experiences and migrants' well-being over the life-course. She acts as an expert on migration policies in Europe. Lulle has published widely, and her contributions include books, edited books, peer reviewed journal papers, book chapters and contributions to encyclopaedias and handbooks on migration. Her recent book, co-authored with King, is Ageing, Gender, and Labour Migration (Palgrave 2016).

\section{Mobilities and waiting: experiences of middle-aged Latvian women who emigrated and those who stayed put}

\begin{abstract}
By revisiting de Beauvoir's feminist arguments on ageing I interrogate work-related (im)mobilities of women in two contexts: migrating in middle-age or pre-retirement, and ageing 'in place'. The data derive from in-depth interviews with currently middle-aged Latvian labour migrants in Europe and non-migrants in Latvia. Ten life stories of migrant women are matched with ten life stories of women who never migrated, but have had similar work-life transitions and care responsibilities. Work-related mobilities are conceptualised along three interrelated dimensions: first, risk-taking in relation to career and income-
\end{abstract}


generating work abroad; second, 'waiting' and enduring versus enjoying employment towards retirement; and third, post-retirement for both groups of women and post-return experiences of return migrants. I demonstrate how these mobilities are similar, but also diverge in migrant and non-migrant narratives due to the capability of these women to control their own mobility. I argue that power relations arising from gender and ageing are important for a more nuanced understanding of how hopeful meanings attached to social and geographical mobilities shape a person's sense of self during ageing.

Keywords: middle-aged women, waiting, (im)mobilities, ageing, Europe, Latvia

\section{Introduction}

'..from the day a woman agrees to grow old, her situation changes. [...] But one must not conclude that it will be easy to live from then on. When she has given up the fight against the inevitability of time, another combat opens: she has to keep a place on earth' (Beauvoir 1949/2011, 710).

Simone de Beauvoir devoted considerable thought to ageing already in The Second Sex (1949/2011). When asking the question 'What is life as we age?' throughout hundreds of pages of the The Coming of Age (1970/1996), she arrived at a simple answer: a dignified old age would be 'a period of life different from youth and maturity, but possessing its own balance and leaving a wide range of possibilities open to the individual' (1996, 542-3). We may rightly argue that the (so-called Western) world has become a better place for those who are ageing since Beauvoir pondered the question more than 40 years ago. And yet problems related to pensions, housing, and leisure for the aged remain socio-historically unequal and the response to them geographically uneven. It is not only the ageing person who has a responsibility to change himself or herself; society too has a responsibility to ensure that the old and the ageing have access to what they need to live fulfilling lives-social structures, cultural attitudes, and the opportunity to influence what it means to grow old. Accordingly, I argue that feminist geographers need to insist on continuing Beauvoir's quest also in the present day. I propose a contribution to analysing the potentially life-changing mobility 
strategies of migrant and non-migrant women who begin to imagine what their lives might be like in later age. I also pay particular attention to the culturally- and structurally-shaped abilities and constraints that influence women's control over their own mobility choices, which stem from power relations determined by gender and ageing.

The research participants presented in this paper are mature women in their late forties, fifties, and early sixties. 'Why talk about ageing so early?' many wonder. Indeed, when discussing work-related mobilities - career, social mobility, or outward (geographical) mobility - we most often imagine young people. The forties are strongly associated with the realisation that one is ageing, but the meaning of this realisation was mainly attached to ageist and sexist encounters (Lulle and King 2016). We observed how women who migrated to the UK and elsewhere in Europe improved their economic and psycho-social wellbeing, and gained a sense of self-worth abroad; their perceptions of ageing were more positive after migration. But we still know far too little to explain these differences with confidencewhich particular social and geographical mobility strategies and immobility realities are related to ageing, and which should be attributed to international migration? Therefore my main research question here is: What do mobility and immobility mean to the women who make the decision to move and those who decide to stay put?

The remainder of the paper unfolds as follows: The first part conceptualises linkages between ageing, mobility, and feminist geography. The second part presents the methodology used and introduces the research participants. The third part contains an analysis of work and income-generating mobilities among migrant and non-migrant women, paying special attention to the contexts in which mobility and immobility change their meaning in relation to ageing.

\section{Theorising work-related (im)mobilities while ageing}

Although middle-aged and older migrant workers still remain understudied in migration literature, my empirical data suggest that middle age and pre-retirement time in working lives can be seen as new beginnings - as a potentially emancipating and mobility-rich period of life. Such an empirically informed vantage point not only gives voice to women who restructure their lives while ageing; it is also a more potent vehicle for unpacking gender- and 
ageing-related power relations. This also makes it possible to explore the cultural and social conditions that require different modes of mobility to achieve a better life towards older age. Therefore I bring together feminist arguments on ageing with mobility studies, and I make three key arguments to frame my subsequent analysis.

First, Heinämaa (2014) sees Beauvoir's The Coming of Age (Beauvoir 1970/1996) as the methodological twin sister of The Second Sex (1949/2011) and, thus, as a manifesto for a paradigmatic change in how we see and experience the processes of age and gender. I find this observation to be fruitful: we can achieve greater depth of analysis, and more compelling and revealing results, if we embrace ageing similarly to the way we understand gender-as an all-permeating quality of the life course where notions and practices of ageing, lived time, and time still to be lived shift and twist. In Beauvoir's writings, ageing waylays women, and there is no escape from physiological ageing. However, and crucially, a woman has the power to accept ageing, and 'her situation changes' (Beauvoir 1949/2011, 710) or, in other words, she is open to new beginnings in life.

A woman's acceptance that ageing goes on and that she needs to care for her own life and place in the world is precisely the productive nexus where feminist arguments come together with much-needed research on the contemporary lives of middle-aged and ageing women. Moreover, in a world where some women stay put and others migrate, the struggle to find and to keep a place in the world can no longer be confined within the static unit of a single country.

Second, I bring these arguments on ageing into dialogue with mobility studies. Feminist geographers have made significant contributions to the gendered politics of mobility (see the review by Yeoh and Ramdas, 2014). Mobility is usually lauded as good for women's lives. In a rich overview of how mobility shapes gender and vice-versa, Hanson (2010) particularly emphasised the power relations embedded in various forms of mobility/immobility. These can be teased out through nuanced attention to contexts (2010; 11); we should also ask how certain forms of immobility could be a positive choice by women themselves in their own relevant life contexts. Mobility can be enacted only if there are 'moorings' (Hannam, Sheller, and Urry 2006) - things, people, and processes that stay relatively put. Materialities, together with social and political control over human mobilities, 
'fix' us to places, at least intermittently, and we need to know how these 'moorings' play out in the lives of women who age.

For Beauvoir, a woman's lack of control over her own life resulted in passive and contingent waiting throughout life: '... her whole existence is a waiting since she is enclosed in the limbo of immanence and contingency and her justification is always in someone else's hand' (Beauvoir 1949/2011, 736). Fortunately, feminist geographers have come up with the valuable concept of 'active waiting', which helps to provide important nuances in actual experiences of ageing, gender, and mobility (Bissell 2007; Conlon 2011, 354). Moreover, the notion of immobility as a form of 'waiting' holds promising potential for understanding both migrant and non-migrant women's (im)mobilities (Gray 2011). People 'wait' also in hope, and prepare for something that should come once the waiting period is over. Thus, the notion of 'waiting' can become a precious tool for understanding the changing contexts of women's lives. In the context of Ireland as an emigration country, Gray $(2011,422)$ has distinguished three modes of active waiting: waiting for an opportunity to migrate, waiting to return to one's country of birth, and waiting for an absent family member or friend to return. All these forms of waiting are relevant to both migrant and non-migrant women in an emigration-prone society such as Latvia.

Third, Monk and Katz (1993, 19) strongly advocate a life-course approach in understanding the mobility circles in women's lives. They convincingly draw on Bateson (1990) and the notion of 'composing a life'. Women make many new beginnings throughout life's course, including work-related moves while ageing. Drawing on data presented later in this paper, at least three prominent 'beginnings' can be distinguished in employment-related mobilities: getting or maintaining a job, new earning prospects, and new perspectives on retirement. As Sachs $(1993,158)$ has concluded, ageing can be seen as the sum of 'earlier life experiences and wider world events [that] have shaped the conditions in which they live.' These temporal contexts are at the core of my investigation into what mobility and immobility mean for women themselves in the diverse circumstances of their lives.

\section{Context and notes on method}


Like many other European societies, but more so than most, the Latvian population is rapidly ageing due to a low birth rate and large-scale emigration. During the decade 2000-2010 the population aged 65+ increased from 14.8 to 17.4 per cent of the total (CSB Population 2015).

In the broader context of the lives of post-Soviet women, personal experiences and global events can pull the understanding of ageing in opposite directions: in terms of the 'felt' dimension and expectations, women feel younger and more forward-looking; in terms of accumulation of income-more unstable and pessimistic about the future. In everyday discourse, the objects, behaviours, and knowledge related to Soviet times (before 1991) are seen as 'old'. In terms of future pensions, the economic and social conditions of recent years are particularly important. The average monthly wage reached a peak (1997-2016) in December of 2015: $664 €$ per month. However, persistent long-term unemployment is a stable trend for 54-65 year olds, who comprise about one quarter of all unemployed (CSB Unemployment 2017). Underemployment and unregistered unemployment is an equally persistent trend within the pre-retirement population. The average monthly old-age pension in Latvia in 2009-10 was $230 €$, and almost $300 €$ in 2016 , while more than 20,000 pensioners receive pensions of less than $100 €$ per month (CSB Pensions 2017). Such an income is too low to make ends meet. Moreover, the gender pay gap in Latvia in 2014 was 17.5 per cent (Eurostat, GPG 2016).

During the years 2010-2014, I interviewed fifty Latvian migrant women who migrated internationally the first time when they were in their forties or older. Out of these, I select then broadly representative cases of analysis in this paper. In 2016 I interviewed ten women of the same age group, who had never migrated internationally, but, migration apart, had matching profiles to the ten migrant women. The non-migrant participants were added so that I could compare the experiences of women, in particular their experiences of ageing, whose early lives were spent under the Soviet regime, and who had similar work histories and care arrangements, but differed in their choices regarding migration. Two of the participants had four/five children, four were married and never divorced, four were single without children, while the rest were mothers of one to three children and were either divorced, widowed, or had lived separately from their partners for many years. All had some age-cohort acquaintances abroad. Eight had higher education obtained at various stages of life, while the rest had secondary or professional educations and had enrolled in continuing education in 
response to occupational changes in life. Migrant participants in their 40s-60s usually worked in low-paid, lower-skilled jobs abroad regardless of their previous education and work experience. Most were earning the host-country minimum wage or slightly more. However, minimum wage levels earned in Western Europe allowed them not only to accumulate savings, but also to buy property in Latvia and to travel.

\section{Mobility in the context of occupation}

Let us begin with questioning what work-related (im)mobility means in relation to the mother's role. Providing material resources was clearly a key factor for many of the women who went abroad; either they needed to provide care for children who were still at school or university, or who were trying to live independently, but were still in need of monetary support. Sanita (divorced, in her forties) is a seamstress by training and a housewife. In 2007 she migrated to Ireland. The money she earned working in a factory abroad, and the cheap and convenient air transport connections, allowed her to visit Latvia each month. However, after the economic crisis in Ireland in 2008, she soon moved to Guernsey to work as a waitress. For Sanita, her duties towards her children encouraged, even compelled her to become internationally mobile. Low wages and underemployment in Latvia strengthened her choice to move abroad. She had capital - could speak English and had some initial savings to go abroad.

Zinaida (60) was also educated as a seamstress but became a casual worker, and experienced long years of underemployment while caring for her three children. Her first spatial mobility was to pursue her profession as a seamstress in the capital city, Riga. Soon after, she married and moved to a town in central Latvia, where her husband's family originated. Her children were born, she took a typing job in an office close to home. But she divorced after only a few years and, lacking financial help from her former husband, she moved back to her mother's country house in the eastern region of Latgale. The region suffered economic depression throughout the 1990s and 2000s, and she never pursued her work as a seamstress there. Yet, living in the countryside, owning pigs, cows, and chickens, and tending the family vegetable garden helped her to push through more than a decade of casual work and underemployment. 
I was taking whatever jobs were available: small private shops, schools, helping in other people's farms. It was not easy at all [...] But I managed to get my children through school. All of them became decent people, all have tried working in England, two finished university, and all of them have their own flats.

Zinaida took care of her three children and worked; she never migrated internationally herself, but her children did. Moreover, she emphasised that she never wanted to join her children abroad. She was awaiting them at home (returning to Latvia, as one had already done), and she was celebrating the upward social and geographical mobilities of her children-opportunities that had been enabled by her efforts in economically constraining contexts.

Other migrant participants, who had fulfilled their care-giving responsibilities, emphasised that they finally felt free to start thinking about themselves. Or rather, they were reminded by their grown-up children that a new beginning should start, as Agrita's story ilustrates. Agrita (in her fifties) is a highly skilled specialist who had worked in various municipal-level institutions. When she was invited by her classmate to 'make a change' and join her abroad, Agrita consulted her children who had just finished secondary school:

Then I asked my children: What would happen if I went abroad for four months? They said: Mum, just go, go, and start thinking about yourself!

Like all of my participants, Agrita was raised in a socialist society. Beauvoir provided numerous examples of how ageism affects paid employment: certain skills are perceived as 'out of date', and older people are widely regarded as being less able to endure and adapt than younger people (1996, 273-381). However, as Beauvoir emphasised, individuals themselves often develop practices that help them not only to compensate for biological ageing, but to become even better than their younger co-workers due to their considerable life and work experience. If both of Beauvoir's books, The Second Sex and The Coming of Age, seem 'outdated' today, it only confirms how profoundly influential they were. 
Despite the fact that some of the participants interviewed experienced discrimination due to their Soviet education being 'out of date', none of the women complained about an inability to endure work or of being slower than their younger colleagues. On the contrary, strength and endurance were what they emphasised about themselves while ageing. The crucial differences between the stories were that migrant women were ready to risk and embrace uncertainties - to change professions completely while ageing, while those who remained in Latvia emphasised persevering in their workplaces in Latvia so as not to risk becoming unemployed. This was not due to a biological decline in strength, but rather to the combination of ageism and the small size of the labour market in Latvia, where losing a job in pre-retirement age must be avoided, even at the cost of enduring inferior work conditions.

Inga and Anita are both in their late fifties. Inga left her media job in Latvia due to stress at work and a tense relationship with her boss. She chose to go abroad. 'I was very aware that I could not get a new job at my age, my level, and in my occupation in Latvia anymore. The market for journalists is simply too small.' In 2009, during the economic crisis, Anita also left her job at one newspaper and moved to another:

'I felt totally exhausted and empty after thirteen years of running around and just scratching the surface of the news. [...] It was risky [to switch jobs], insecurity was high. I could hear and see all around me-if you drop out of the media job market, the circles are small. [...] But I was lucky. I like my job and I will try to stick with it until I retire.'

Inga went to Portugal, then to England and then to Austria, and found employment in a hotel. However, she does not regret the change and feels even happier working outside her original profession. As she said: 'I was always studying in Latvia, I was always going for something new.' She also has diplomas in nursing and human resources, so the long years of professional experience spent in journalism were not her only valuable 'occupational' resource. The most important thing for her was what Inga referred to as an intrinsic need to feel free; she felt great curiosity about other cultures and languages, which in turn helped her to grow as a person. Inga, like many other migrants, continuously referred to people from Latvia of her own age and older whom she had met abroad; the most striking thing about 
them was how they had rejuvenated themselves physically, mentally, and professionally, even if the jobs they found were not within their original professions.

Anita, on the other hand, emphasised that she would never consider a move abroad because she has 'everything' in Latvia: family, relatives, her native culture and language, as well as a summer house. However, in her dreams Anita wanted to change her profession in her early fifties. She would have liked to work with children in hospitals, with underprivileged children, organising special events for them. 'But it's just a dream, just an idea at my age,' she said. For her, changing occupations would be too risky. She did not experience a sense of being 'stuck in one place' (Burrell and Höschelmann 2014: 14), as did Inga, but rather felt a pragmatic sense to stay put. Another factor is health security; Anita's current workplace pays for health insurance. Changing employers or becoming self-employed would mean a high risk of losing this financial support for healthcare while ageing.

Although almost all of the women, migrant and non-migrant, whom I interviewed wanted to change their professional activities in mature age, the typical expectations for nonmigrants are similar to those of Marite (below), and are related to the psychological and cultural contexts in which they live-changing jobs as an ageing woman could potentially jeopardise the little security they felt they had achieved:

I had a job offer recently, but decided not to take the risk. It was not so much that I would have been scared of change, but I don't want to move back and forth any more, I have a stable job, I know the people I work with, and I hope to stay here until I retire. (Marite, in her fifties, never migrated)

The main contextual difference becomes apparent: non-migrant participants avoid changing professions or employments and relate their hesitation to fear of losing a place of work due to ageing. Let us move on to the next circle-waiting for pensionable age and the immobility of waiting (Gray 2011).

\section{Waiting for retirement at home and abroad}


Under the Soviet system women usually retired at age 55. But nowadays life expectancy is steadily increasing and people are expected to work longer. Non-migrant participants stressed that it is too obscure to understand what will happen with pensions; that pensionable income will be so small anyway that it is better not to think about it at all.

Most of those who are currently in their mid-forties and older in Latvia cannot hope to receive decent old-age pensions because their taxable incomes have been so low. One of the alternatives is to rely on generational contracts with their children and grandchildren to support the old and the poor in the extended family. This is seen as less desirable by both migrant and non-migrant women; however, the latter group do not question how 'good' such a life in older age might be as much as the former do. Laima (in her late forties) never migrated, and relies on generational support: when her children grow up, they can help her financially. She is the mother of four children, currently a housewife because her two younger children are still small and she cares for them at home. Since they were born when she was in her mid-forties, she feels more fear that ageing may mean she is unable to fulfil her care role as a mother, than she does about her own income in old age:

I am a person who does not think about the future, if I have money I use it today. Sometimes I fear ageing because I won't be able to care for my kids; I feel sorry for them. Sometimes my husband laughs and says that we need to look for a school with a handicap-accessible entrance so I could go there in my wheelchair to greet my children. [...] I do not think that we will have any pensions, but I trust that I have given enough to my children and I will receive something back from them.

Here I want to draw on Kirkpatrick's (2014) dialogical reading of Beauvoir's arguments on ageing and her questions regarding maternity. There are not only multiple 'new beginnings' and new mobilities in a woman's life, but also multiple 'waitings'. Too often the pain and suffering of motherhood 'is comfortably left unquestioned' as it is with the realities, including material marginalisation, of ageing women (Kirkpatrick 2014, 286). In the case of Laima, her choice of prioritising motherhood and non-employment is experienced against the background of her own acceptance that she is beginning to age. 
This was a usual reaction of my non-migrant participants, leaving unquestioned or even actively avoiding thinking about the size of their old-age pension. This is accompanied by a deep distrust of the pension system and state budget matters in Latvia. Baker and Beagan (2015) have demonstrated that trust and distrust is also related to geographical imaginations of how people could access services and support different places. My participants avoided calculating how much they could receive; none of my participants had done it, and not even those who were retired at the time of interview knew beforehand how much they would receive. This avoidance is qualitatively very different from waiting as a productive, calculative and positive immobility in Gray's (2011) research about Irish people. I interpret this bracketing off of the retirement amount as due not only to historical changes in Latviaas income earned under the Soviet system counts little towards the accumulation of one's pension-but more importantly, due to state-imposed modes of waiting, such as failing to explain clearly to ageing workers what they can expect to receive as a pension. These uncertainties have the disciplining function of making somebody wait (Schwartz 1974; Ozolina-Fitzgerald 2016; Sullivan 2017, 21) in ignorance and therefore less able to plan future mobilities against the available income. Most said that even if they inquired at the Latvian welfare institutions, they were told to come back when they had reached retirement age. This discipline of waiting in enforced ignorance extends even to the rare cases when non-migrant participants had managed to obtain cumulative life insurance funds. They avoid calculating and as a typical response said, 'We will see when the time comes.'

Avoidance of calculation and distrust of the pension system are in sharp contrast to what the migrant participants related. The attitude of distrust in the Latvian pension system is strongly geographically contextual. As soon as migrant women actively sought and contacted welfare institutions elsewhere in Europe, they began to trust in their future income from oldage pensions. Alma (in her sixties), who worked in Guernsey where there is a substantial Latvian migrant community for ten years, was gradually introduced to her retirement future. As she was approaching retirement age, she received letters from the Guernsey welfare system every second year with clear calculations showing how the pension earnings of each working year were accumulating towards her old age pension. She learned the amount of her retirement entitlement from Latvia-166 euros per month for her 33 years of employment in the retail sector - only when she actually retired in 2014 . Her ten years of employment in the 
agriculture sector in Guernsey entitled her to 47 British pounds a week. Differences in how much ageing workers can accumulate in Latvia and how much elsewhere in Europe have enacted another 'new beginning' - active waiting as anticipation (Gray 2011, 421) for pensions, as ten years in the UK is worth more than 33 years in lower-paid jobs in Latvia. Remaining abroad for a better pension can become a positive strategy of 'waiting.'

However, retirement anticipation can still cause 'unwished for' immobilities. I already introduced Marite, in her fifties, who never migrated; she 'almost' went abroad herself, but changed her mind the night before she and her friend were to board the plane. Marite became scared considering such a radical move as leaving Latvia:

... I cannot describe it, maybe I got scared... I changed my mind. She went and I stayed. Now she is still in England, she cannot return since she wants to stay there for at least another ten years and await her British pension.

Note how Marite describes her friend in England as being immobilised there due to the pension issue. In this case, if the ideal is to live in Latvia in old age, perceptions and assumptions of migrant women's immobilities may help those women who stayed put to feel better about ageing in their home country. Return is the topic of my final analytical section.

\section{Post-retirement and post-return mobilities}

Research has recently emerged on return migration in older age (see Barrett and Mosca 2013) or, conversely, on becoming 'stuck' in the country of destination, unable to return 'home' due to the lack of social systems that would provide sufficient health and social services for former 'guest workers' who now have aged (Hunter 2011). Latvia as 'home' in old age was crucial for most of my research participants. However, in migrant stories, the idea of winning one's own place in old age was irreducibly entwined with return mobilities. But let me start with the non-migrant interviews.

My research participants eagerly accepted the realities of 'growing old' when they spoke about life beyond paid employment. Seeing themselves as mainly (but not always) 
independent women in older age, participants aligned with Beauvoir's $(2011,813)$ claim that 'work [alone] today is not freedom.' To change a life for better in older age, the most crucial factor was to obtain a secure place to live and a secure old-age income. Only then could gardening, repairing a second home, and many more passions be pursued. However, earlier life experiences shape what life in older age can be and where.

Zinaida (60), introduced above, who had experienced long years of work alternating with underemployment and time out of work spent caring for her children, opted for early retirement in Latvia. During the interview Zinaida was living in her daughter's apartment and providing care for her grandchildren, when necessary.

I would not complain about my life. I am very proud of my children; all of them grew up to be good, hard-working people. All of them managed to get their own living space. I would not complain [...] only [almost whispering] if I had my own space.

Although the gendered image of an ageing grandmother who happily sacrifices her life for the younger generations is still strong in present-day Latvia. This goes unquestioned as one of the hardships of motherhood (Kirkpatrick 2014, 286), my participants unconsciously recited Beauvoir's $(2011,712)$ warning: 'Living by proxy is always a precarious expedient. Things may not turn out as one wished.' It is quite difficult for the long-term underemployed and for low-wage earners who never migrated to maximise income before retirement and find a secure space of their own in old age.

Post-retirement care mobilities are traditionally related to grandmothering and, as noted earlier, may be idealised through generational support. However, my participants did not anticipate such lives for themselves. Most resisted dependency on the younger generation (Utrara 2011), but not all could escape it, due to economic constraints. The ideal for every interviewee was to have her own living space and to be able to control the time she spent caring for her grandchildren. Since many women who expect to retire in the next 10-15 years will have a very low income of their own, this ideal may remain in stark contrast with reality.

A different theme, and one that is equally important for my participants, is a sense of self, of feeling at home in the world when they have retired. Old age can come as a shock and retirement itself can push one towards geographical mobility and the quest for a more 
meaningful way of being in the world. Let us hear Anita's (in her fifties) observation of one of her retired friends:

One of my friends retired, she had good salary, a good pension. But she felt totally isolated, away from life, from everything. So she began taking very long walks in Riga's parks. She started studying English but then went to Sweden through a church. Through the church she got in touch with a Latvian family there and worked as a 'live-in' nanny in Sweden. She thought, it does not matter where her body is-either she is isolated in Riga or she lives in the middle of a forest in Sweden and is useful for this Latvian family in need of care. But she returned recently and now she says she is very happy. She wants to be in Latvia and can appreciate all of the things available to her here.

In Deutscher's $(2014,35-36)$ reading of Beauvoir, possibilities for a better life in old age are fundamentally linked to how we have previously lived and continue to be engaged in matters in which we are passionately interested. However, retirement still can be felt as structural oppression and boredom, as in the case of Anita's friend. Only after the retired woman went abroad did she realise how much she belonged to Latvia and how passionate she is about matters beyond employment-her friends, the memories of her past in Latvia, and the whole environment around her.

As expressed in the quote above, the return is the most important mobility for my migrant participants. Although almost all participants reported that the time of ageing is when they realised that they finally have the chance to live life to the fullest-freer from economically-imposed mobilities, freer from care for others - for migrant women old age was idealised as fully coming home. The participants felt that they have control over their income abroad and therefore, hopefully, over their financial security upon the return. They usually began imagining post-return scenarios when they first began saving abroad. And these savings were, again, typically made with the purpose of acquiring their 'own space' in Latvia - buying a flat or a house, or repairing the existing one. Either in preparation for retirement or having already retired abroad but still working part-time, migrant women 
continue to prepare for their own homes in Latvia, financially and psychologically. In sum, they embrace old age positively precisely due to their ideas of return.

\section{Concluding discussion}

Inspired by Beauvoir's feminist arguments on ageing, in this paper I asked what mobility and immobility mean for middle-aged migrant and non-migrant women. By choosing between international mobility and staying put, my participants - directly or indirectly-'agreed to grow old' (Beauvoir 1949/2011, 710), and to strive to create better lives for themselves in old age. My contribution lies in spatially diversifying the feminist arguments regarding ageing through inquiry into women's mobilities in both migratory and non-migratory contexts.

Migration is just one life-changing type of mobility, although among the more radical options. However, we should keep in mind that non-migrant women are also geographically mobile at the national and regional scales.

In Susan Hanson's $(2010,14)$ critical review of literature on how gender shapes mobility and vice versa, one of her central findings stands out: spatial mobility is empowering. However, she also posed a challenging question: Why do feminists rarely recognise and celebrate a woman's choice to stay put and opt for less spatial mobility in order to achieve a better life?

Drawing on feminist geographers' (Conlon 2011; Gray 2011) conceptualisation of 'waiting' as a distinctive, active, and fulfilling form of relative immobility, I have described how waiting plays out and what it means to women as they age. Waiting permeates women's lives to a great extent also in the present day, almost seventy years since The Second Sex was published and Beauvoir claimed that women are somewhat immobilised by waiting throughout their whole lives. My participants 'waited' until their children became selfsufficient, 'waited' in known, but unsatisfactory, workplaces even if they wanted to change employers, 'waited' for retirement, and migrant women 'waited' for return.

When admitting, sometimes subtly, that they do age, the participants in my study described embracing 'new beginnings' in their lives through mobilities. In terms of mobility choices these 'new beginnings' were prominently shaped by the broad overlapping contexts of post-socialism and more global changes towards neoliberal social policies - a later 
retirement age and subsequent insecurities for the ageing. Simultaneously, women's own past mobility choices and constraints, which are embedded in gendered power relations, shaped their current positions and their ideas about the future in old age.

I distinguished between three main processes where changes in occupation and workrelated social and geographical mobilities cluster while ageing. First and unsurprisingly, those women who never migrated were more cautious about changing jobs-better not to risk the insecurity of change and remain in a known workplace. These worries cannot be explained by women's passivity per se. Avoiding risky mobilities is related to the constraining gender structures in Latvian society, ageism, and, crucially, the small scale of the Latvian economy. Health-care benefits and achieving a stable income 'fix' or tie people to wait for retirement in certain workplaces. Among those who migrated, few actually worked in their pre-migration professions. And if they did, it was in the service sector, for instance taking jobs in shops and restaurants. However, migrant women did not see their lower-skilled employment opportunities abroad as socially downward mobilities. Migration requires mobilisation in many domains of life: learning a new language, adapting to a new culture, and becoming accustomed to different types of work relationships, to name a few. Women repeatedly emphasised their feelings of 'rejuvenation' and 'empowerment' though their ability to earn money, but also and especially because they learned a new language, became independent travellers, and quickly obtained new professional skills. Also, grown-up children were often the ones to encourage their mothers to be mobile in middle-age, which is partly in line with Beauvoir's warning that justification for a woman's movements is in 'someone else's hand' (Beauvoir 1949/2011, 736). But I also want to respond to Hanson's (2010) question on 'spatial confinement', which is rarely lauded by feminist geographers. Some of my participants, for example the journalists Anita and Zinaida, who endured many years of underemployment and casual work, never wanted to migrate. Everything they passionately cared about they already had in Latvia, despite the risks and hardships of, perhaps, a financially grim old age. Their deliberate choice to 'stay put' in a society characterised by a large-scale emigration is certainly in need of greater investigation by feminist geographers and mobility researchers, in a variety of empirical contexts.

Second, for those who would become pensioners in 10-15 years' time, the choice to emigrate was seen as a pragmatic outward and upward mobility for increasing the possibility 
for better financial security in old age. The current system of old-age pensions in Latvia, under which most pensioners receive a low pension income, is a direct consequence of the low economic growth in Latvia during the period of transformation to a market economy in the 1990s. Avoidance of thinking about and calculating future old-age income was pronounced among the women who never migrated, but those who migrated quickly developed more a pragmatic demeanour and a positive forward-looking approach to old age. I interpret these differences as embedded in the political power relations between an ageing person and the state. My migrant participants felt that they had gained knowledge, and thus control, over the amount of their future pensions. Moreover, power relations are even more negative towards women in cases when they prioritise care for children over paid employment for a considerable portion of their lives. As Laima said: 'I put my hope in my children.' However, moving abroad to earn a pension could also turn out into a secondary type of 'waiting': working towards and waiting for retirement abroad, but feeling discontented with her current situation and waiting for the day when retirement would free her for a 'new beginning' - returning to Latvia.

Third, my findings strongly point towards women's desire for an independent life in older age. For most migrant women, the emigration project was envisioned as temporary - a period of work abroad until retirement, since pensions are transportable within the EU. And, while working abroad, they found their employment mobilities to be purposeful and positive- were working towards returning 'home' to Latvia in a better financial position than they would have had, had they stayed put. Both groups of women longed for their own spaces in old age, although past and current cumulative income continues to shape inequalities among women in old age as well. Employment and earnings abroad for women pave the way to a meaningful return, as a new beginning in the lives of older women. For migrant women, looking forward to old age in one's own space radically shapes their understandings of mobilities and waiting while ageing in positive terms.

\section{References}

Baker, Kelly and Brenda Beagan. 2015. “'Unlike Vancouver ... here there's nothing':

Imagined geographies of idealized health care for LGBTQ women". Gender,

Place \& Culture: 1-14. 
Barrett, Alan and Irene Mosca. "2013. Social isolation, loneliness and return migration: evidence from older Irish adults". Journal of Ethnic and Migration Studies 39(10): 1659-1677.

Bateson, Mary C. 1990. Composing a life. New York: Plume/Pinguin Books.

Bissell, David. 2007. “Animated suspension: Waiting for mobilities”. Mobilities 2 (2): 27798.

Burrell, Kathy. and Kathrin Höschelmann. 2014. "Introduction: understanding mobility in Soviet and East European socialist and post-socialist states."” In Burrell, K. and Höschelmann, K. (eds) Mobilities in socialist and post-socialist sates. Societies on the move, Basingstoke: Palgrave McMillan, 1-22.

CSB Pensions 2017. Central Bureau of Statistics, average levels of old-age pensions, http://www.csb.gov.lv/statistikas-temas/sociala-drosiba-galvenie-raditaji$\underline{30402 . h t m l}$

CSB Unemployment 2017. Central Bureau of Statistics. In 2016, unemployment rate in Latvia was still reducing:http://www.csb.gov.lv/en/notikumi/2016unemployment-rate-latvia-was-still-reducing-46137.html

CSB, Population 2015. Central Bureau of Statistics. http://www.csb.gov.lv/category/tagi/Iedz $\% \mathrm{C} 4 \% \mathrm{ABvot} \% \mathrm{C} 4 \% 81 \mathrm{ji}$

Conlon, Deirdre. 2011. "Waiting: feminist perspectives on the spacings/timings of migrant (im)mobility". Gender, Place \& Culture, 18(3): 353-360.

De Beauvoir, Simone. 1970 [1996]. The coming of age. Trans. by Patrick O'Brian. Norton \& Company: New York and London.

De Beauvoir, Simone. 1949 [2011]. The Second Sex. Trans. by Constance Borde and Sheila Malovany-Chevallier Vintage: New York.

Eurostat, GPG 2016. Gender Pay Gap, tables:

http://ec.europa.eu/eurostat/statisticsexplained/index.php/Gender_statistics

Deutscher. Penelope. 2014. 'The Sex of Age and Age of sex. In S. Stoller (ed) Simone de Beauvoir's Philosophy of Age: Gender, Ethics, and Time. De Gruyter: Berlin and Boston, pp. 29-42. 
Gray, Breda. 2011. Becoming non-migrant: lives worth waiting for, Gender,Place \& Culture, 18 (3): 417-432.

Hannam, Kevin, Mimi Sheller, and John Urry. 2006. "Editorial: Mobilities, immobilities and moorings". Mobilities 1(1): 1-22.

Hanson, Susan. 2010. "Gender and mobility: New approaches for informing sustainability." Gender, Place \& Culture, 17(1): 5-23.

Heinämaa, Sara. 2014.’Transformations of Old Age: Selfhood, Normativity, and Time.” In Silvia Stoller (ed.), Simone de Beauvoir's Philosophy of Old Age. Indiana University Press, pp 167-87.

Hunter, Alistair. 2011. Theory and practice of return migration at retirement, Population, Space and Place 17(2): 179-192.

Lulle, Aija. and Russell King. 2016. Ageing, gender and labour migration. London and New York: Palgrave Macmillan.

Monk, Janice and Cindi Katz. 1993. "When the world are women?” In Katz, C. and J. Monk (eds) Full circles: Geographies of women over the life course. Routledge: London and New York. Geographies of women over the life course. Routledge: London and New York, 1-26.

Ozolina-Fitzgerald, Liene. 2016. A state of limbo: The politics of waiting in neoliberal Latvia. British Journal of Sociology 67(3): 456-475.

Schwartz Barry. 1974. "Waiting, exchange, and power: the distributions of time in social systems". American Journal of Sociology 79(4):841-70.

Sullivan, Esther. 2017. "Displaced in Place: Manufactured Housing, Mass Eviction, and the Paradox of State Intervention." American Sociological Review DOI: $10.1177 / 0003122416688667$

Utrata, Jennifer. 2011. "Youth privilege: Doing age and gender in Russia's single-mother families." Gender and Society, 25 (5): 616-641.

Yeoh, Brenda S.A. and Kamalini Ramdas. 2014. "Gender, migration, mobility and transnationalism." Gender, Place \& Culture, 21(10): 1197-1213. 